\title{
Effect of Lithium Carbonate on Activity Level and Circadian Period in Different Strains of Rats
}

\author{
THOMAS HAFEN ${ }^{1}$ AND FRANZISKA WOLLNIK \\ Department of Biology, University of Konstanz, D-78434 Konstanz, Germany
}

Received 30 December 1993

\begin{abstract}
HAFEN, T. AND F. WOLLNIK. Effect of lithium carbonate on activity level and circadian period in different strains of rats. PHARMACOL BIOCHEM BEHAV 49(4) 975-983, 1994. - Lithium, an important pharmacological agent for the treatment of manic-depressive illness in humans, is known to lengthen the circadian period in a number of different species. Recent experiments, on the other hand, suggest that pharmacological agents may affect the circadian system indirectly through an increase or decrease of activity. To explore the interaction between pharmacological and activity effects on the circadian system, lithium was administered chronically to three different strains of rats ( $\mathrm{ACI}, \mathrm{BH}$, and LEW) while wheel-running activity was studied quantitatively. Two of these inbred strains (BH and LEW) show profound abnormalities in their circadian activity rhythms, namely, a reduced overall level of activity and bimodal or multimodal activity patterns. Wheel-running activity was monitored for 4 weeks under baseline conditions, followed by 3 weeks with lithium treatment $\left(0.3 \% \mathrm{Li}_{2} \mathrm{CO}_{3}\right.$ administered with food) and 4 weeks with normal food. Treatment with lithium (average intake per day $=3.6 \pm 0.2 \mathrm{mg}$ ) consistently decreased both the overall level and the circadian amplitude of the activity rhythm. The free-running period $\tau$ was slightly lengthened during lithium treatment, while the most dramatic effect on period was observed after lithium withdrawal. Correlation analysis, however, revealed only a small negative correlation between activity level and period length, which proved significant only for animals of the $\mathrm{ACI}$ strain. Our data support the traditional interpretation that lithium lengthens circadian period by a direct pharmacological effect on the circadian pacemaker rather than through indirect effects of activity feedback.
\end{abstract}

Circadian rhythms Lithium Activity feedback Genetic differences Inbred strains

LITHIUM is one of the most extensively studied chronobiologically effective agents [for recent reviews, see $(17,21)$ ]. Its period-lengthening effect on circadian rhythms has been documented in a great variety of species, e.g., desert cactus (8), cockroaches $(15)$, molluscs $(42)$, hamsters $(4,15)$, desert rats (8), rats $(24,41)$, mice (33), squirrel monkeys (46), and humans (16).

The period-lengthening effect of lithium is of special interest with respect to the hypothesis that there may be an association between the pathophysiology of affective disorders and disturbances of circadian rhythms $(22,48)$. Several studies in humans have demonstrated that many circadian rhythms are phase advanced in depressed patients compared to controls [reviewed in $(12,44,45)$ ]. Because lithium and a few other antidepressant agents $(5,47)$ have been shown to lengthen circadian rhythms in mammals, these results have been interpreted to the effect that the therapeutic effect of these drugs may be based on their phase delaying effect on the circadian pacemaker.

So far, the mechanisms responsible for lithium's chronopharmacological actions are not known. It has been suggested that lithium could lengthen the circadian period by a) slowing of cellular oscillators, b) by altering the coupling between multiple circadian oscillators, or c) by altering light sensitivity (17). The hypothesis that lithium may weaken the mutual interaction between multiple oscillators is especially intriguing because modifications in coupling strength could theoretically account for changes in period, as well as entrained phase, wave form, and amplitude of circadian rhythms.

An alternative explanation for the effect of lithium and other pharmacological agents comes from recent experiments demonstrating that changes in the free-running period may be

\footnotetext{
${ }^{1}$ Requests for reprints should be addressed to Thomas Hafen, Deutsches Primatenzentrum, Kellnerweg 4, 37077 Göttingen, Germany.
} 
induced by alterations of the activity level. For example, the circadian period of activity rhythms depends on the method of activity recording, i.e., measured with or without a running wheel $(2,6,34,52,53)$. This seems to be due to an ambulation increasing effect of running wheels, and a negative correlation between the number of wheel revolutions and the free-running period has been observed in rats $(39,54)$ and mice (7).

As manipulations of overall activity, e.g., by introducing a running wheel, change the period of circadian activity rhythm, it may be possible that some, if not all, of the observed effects of chronobiologically active agents are due to a change in activity amount or distribution. This notion is strengthened by several studies with antidepressant agents: clorgyline, for example, dampens activity and lengthens circadian period (5), whereas both moclobemide and desipramine increase activity and shorten period length (50). Further evidence derives from studies of the phase-shifting effect of pharmacological agents on the free-running rhythms, in which activity restriction after pharmacological application abolished chronobiological effects (43).

Although the reports on period lengthening by lithium are numerous, only a few studies have quantified activity, and only one has correlated parameters of activity with period changes (38). The present study was, therefore, designed to confirm and extend previous observations, and differs from earlier studies in two important ways: first, wheel-running activity was registered quantitatively before, during, and after lithium application. Second, the effect of lithium was evaluated in three different inbred strains of rats. The first of these modifications was employed to test the possible correlation between overall activity and circadian period. The second modification was designed to further evaluate the effect of lithium on genetically different animals.

METHOD

\section{Animals and Housing}

Male rats of the inbred strains $\mathrm{ACI} / \mathrm{Ztm}$ (agouti), $\mathrm{BH} / \mathrm{Ztm}$ (black hooded), and LEW/Ztm (albino), originally obtained from the central laboratory of the Hanover Medical School (Germany), were bred and raised in our laboratory under controlled environmental conditions (12 L : $12 \mathrm{D}$ cycle, lights on at $0700 \mathrm{~h}$, room temperature $22 \pm 1^{\circ} \mathrm{C}$ ). Eight male rats of each strain, 8-11 weeks old, were singly housed in cages (Makrolon [Becker, Castrop-Rauxel, Germany] Type IV, $35 \times 55$ $\times 10 \mathrm{~cm}$ ) equipped with a running wheel (diameter $35 \mathrm{~cm}$, width $10 \mathrm{~cm}$ ). Groups of four running wheel cages each were housed within ventilated, light-tight, stainless steel compartments. Wheel-running activity of all 24 animals was monitored simultaneously for 14 weeks. Animals had free access to the running wheel; food and water were supplied ad lib. Animals were checked once per week at irregular times during the light phase of the light-dark (LD) cycle or - when kept under constant dark conditions (DD) - by using a red dark room light ( $\leq 0.51 \times$; Kindermann, Germany). At these occasions, animals and remaining food were weighed, food and water replenished, and cages were changed if necessary.

\section{Data Collection and Analysis}

Three magnetic reed switches were mounted on each running wheel axle so that one complete wheel revolution resulted in three impulses. The number of impulses per 5-min interval was recorded continuously by a microcomputer (Apple II +). All subsequent calculations were based on these 5-min counts.
Periods $\tau$ of the free-running circadian rhythm were estimated using the $\chi^{2}$ periodogram $(9,40)$. Harmonic spectral analysis $(14,31)$ was used to verify the presence of characteristic frequencies in the data. Further details of the statistical model underlying these two approaches are described elsewhere $(49,51)$.

In addition, overall level of activity, defined as total number of counts over a 24 -h period given in impulses/day, was calculated. The data were analyzed with a mixed three-way analysis of variance (ANOVA). Differences between strains (ACI, BH, LEW) and experimental groups (treated vs. untreated control animals) were evaluated by a univariate design, whereas differences between treatment conditions (baseline, lithium treatment, withdrawal) were analyzed using a multivariate design for repeated measurements (Wilk's Lambda). Scheffé's multiple $t$-test was used for individual mean comparisons. Pearson's $r$ was used for expressing correlations.

\section{Procedures}

After transfer to the running wheel cages, animals were kept under a light-dark cycle (12 L:12 D) for 3 weeks to accustom them to the new environment. Thereafter, the animals were kept under constant dark conditions. Following the 4 weeks of free-running baseline conditions, the eight animals of each strain were randomly assigned to control groups ( $n=$ 2) with standard diet (Altromin 1314) and treatment groups $(n=6)$ with the same pelleted diet containing $0.3 \%$ lithium carbonate $\left(\mathrm{Li}_{2} \mathrm{CO}_{3}\right)$. Although lithium levels were not measured, this concentration of $\mathrm{Li}_{2} \mathrm{CO}_{3}$ has been shown to be chronobiologically effective $(24,28,33,41,46)$. After 3 weeks of treatment, all animals were fed with the standard diet and activity recordings were continued for another 4 weeks (withdrawal).

\section{RESULTS}

\section{Body Weight, Food Consumption, and Health of Animals}

Measurements of body weight and food consumption are summarized in Tables 1 and 2 . As expected, repeatedmeasures ANOVA indicated significant strain differences in food consumption, $F(2,15)=10.8, p \leq 0.01$, and body weight, $F(2,15)=88.1, p \leq 0.01$, with animals of the ACI $(210 \pm 18 \mathrm{~g})$ strain being generally ligther than animals of the BH $(346 \pm 28 \mathrm{~g})$ and LEW $(352 \pm 22 \mathrm{~g})$ strains. Although animals of the control groups maintained a constant food intake throughout the experiment, animals of the lithium treatment groups showed a substantial reduction $(30-40 \%)$ of food intake during lithium treatment, which was most pronounced in animals of the LEW strain $(50 \%)$. In all three strains, food consumption of treated animals was significantly lower than that of untreated control animals, resulting in a $20-30 \%$ loss of body weight over 3 weeks. After termination of lithium treatment (withdrawal), formerly treated animals showed a significant increase in food intake and body weight. In addition to the reduced food intake and body weight, lithium-treated animals suffered from diuresis and diarrhea and showed an approximately fourfold increase in water consumption. One $\mathrm{ACI}$ and one $\mathrm{BH}$ rat died.

Food intake data during lithium treatment were used to estimate the daily uptake rates of lithium for each animal. In the average, food consumption of $12.3 \pm 0.7 \mathrm{~g} /$ day during lithium treatment lead to an intake of $3.6 \pm 0.2 \mathrm{mg}$ $\mathrm{Li}_{2} \mathrm{CO}_{3} /$ day. 
TABLE 1

EFFECT OF CHRONIC LITHIUM TREATMENT $\left(0.3 \% \mathrm{Li}_{2} \mathrm{CO}_{3}\right)$ ON BODY WEIGHT (g) OF THE THREE INBRED STRAINS $\mathrm{ACI}, \mathrm{BH}, \mathrm{AND}$ LEW

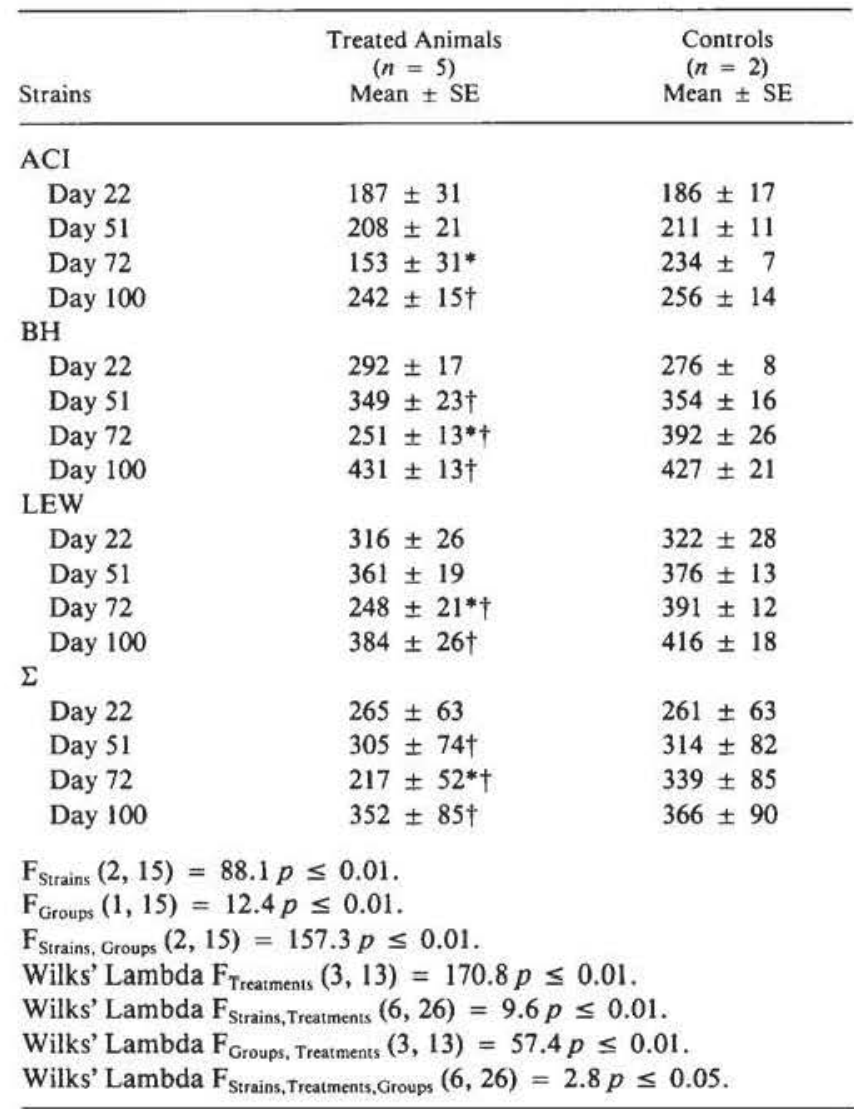

Differences between strains ( $\mathrm{ACI}, \mathrm{BH}, \mathrm{LEW}$ ) and experimental groups (control, lithium treated animals) were assessed using standard procedures of ANOVA (two-way ANOVA), whereas differences between treatment conditions (baseline, lithium treatment, withdrawal) and their interactions with strains or groups were analyzed using a multivariate design for repeated measurements (Wilks' Lambda). Scheffé's multiple $t$-test was used for individual mean comparisons.

* Significant difference from control group.

†Significant difference from previous measurement.

\section{Strain Differences in Baseline Wheel-Running Activity}

Characteristic activity recordings from treated and control animals of each strain are shown in Fig. 1. During baseline conditions, all animals displayed clear free-running rhythms. Periodogram analysis (Table 4) revealed an average circadian period of $\tau=24 \mathrm{~h} 14 \mathrm{~min}$ during baseline conditions, with only small differences between strains (beyond $6 \mathrm{~min}$ ).

The circadian pattern of wheel-running activity was strain dependent (Fig. 2). ACI rats exhibited the strongest activity rhythm characterized by high activity levels and well-defined onsets and offsets of activity. Animals of the BH strain showed weaker activity rhythms with blurred onsets and of fsets and expanded times of activity. LEW animals revealed a lower overall activity level with three distinct bouts of activity about 4 to $6 \mathrm{~h}$ apart (see Fig. 2e). Spectral harmonic analyses (Fig. $2 b, d, f)$ revealed characteristic strain differences in the strength of the circadian component and in the detection of additional rhythmic components in the activity pattern of $\mathrm{BH}$ (approximately $12 \mathrm{~h}$ and $6 \mathrm{~h})$ and in LEW rats $(6 \mathrm{~h}, 4.8 \mathrm{~h}$, and $4 \mathrm{~h})$.

Furthermore, strain differences in overall activity were clearly visible in activity recordings; however, these differences did not prove significant when analyzed with ANOVA (Table 3).

\section{Effects of Lithium Treatment}

As shown in Figs. 1 and 2, lithium treatment clearly affected wheel-running activity. All three strains showed a significant decline in the overall activity level (Table 3). Activity onsets and offsets got very blurred. In ACI rats the center of activity was shifted into the later subjective night (Fig. 2a). The reduction of activity level and circadian activity pattern was reflected by a small reduction of the amplitude of the 24 -h peak in the power spectrum analysis (Fig. 2b). In BH and LEW rats, differences between circadian activity and rest phase became rather small, resulting in a very flat circadian wave form (Fig. $2 c, e$ ), although separate activity bouts were hardly visible. However, power spectrum analyses (Fig. 2d,f) revealed only a minor reduction in the amplitude of circadian as well as ultradian spectral estimates during lithium treatment.

TABLE 2

EFFECTS OF CHRONIC LITHIUM TREATMENT ON FOOD CONSUMPTION (g/DAY) IN ACI, BH, AND LEW RATS

\begin{tabular}{ccc}
\hline Strains & $\begin{array}{c}\text { Treated Animals } \\
(n=5) \\
\text { Mean } \pm \mathrm{SE}\end{array}$ & $\begin{array}{c}\text { Controls } \\
(n=2) \\
\text { Mean } \pm \mathrm{SE}\end{array}$ \\
\hline ACI & & \\
B & $16.1 \pm 1.5$ & $16.0 \pm 1.0$ \\
T & $12.9 \pm 1.4$ & $16.4 \pm 0.3$ \\
W & $18.6 \pm 0.6$ & $16.8 \pm 0.6$ \\
BH & & \\
B & $22.0 \pm 0.8$ & $23.1 \pm 1.0$ \\
T & $14.0 \pm 0.6$ & $23.8 \pm 0.2$ \\
W & $28.5 \pm 1.0$ & $25.7 \pm 1.0$ \\
LEW & & \\
B & $20.9 \pm 0.4$ & $21.8 \pm 0.2$ \\
T & $9.9 \pm 0.5$ & $21.3 \pm 0.6$ \\
W & $22.3 \pm 0.5$ & $21.1 \pm 0.9$ \\
D & & \\
B & $19.7 \pm 0.9 \dagger$ & $20.3 \pm 1.3$ \\
T & $12.3 \pm 0.7^{*} \ddagger$ & $20.5 \pm 1.3$ \\
W & $23.1 \pm 1.1^{* \dagger}$ & $21.2 \pm 1.6$ \\
\end{tabular}

$\mathrm{F}_{\text {Strains }}(2,15)=10.78 p \leq 0.01$.

$\mathrm{F}_{\text {Groups }}(1,15)=108.29 p \leq 0.01$.

$\mathrm{F}_{\text {Strains, Groups }}(2,15)=5.9 p \leq 0.01$.

Wilks' Lambda $\mathrm{F}_{\text {Treatments }}(2,14)=82.17 p \leq 0.01$.

Wilks' Lambda $\mathrm{F}_{\text {Strains, Treatments }}(4,28)=5.43 p \leq 0.01$.

Wilks' Lambda $\mathrm{F}_{\text {Groups, Treatments }}(2,14)=58.65 p \leq 0.01$. Wilks' Lambda $F_{\text {Strains, Treatments, Groups }}(4,28)=2.04$ NS.

Differences between strains ( $\mathrm{ACI}, \mathrm{BH}, \mathrm{LEW})$ and experimental groups (control, lithium treated animals) were assessed using standard procedures of ANOVA (two-way ANOVA), whereas differences between treatment conditions (baseline, lithium treatment, withdrawal) and their interactions with strains or groups were analyzed using a multivariate design for repeated measurements (Wilks' Lambda). Scheffés multiple $t$-test was used for individual mean comparisons.

*Significant difference from baseline condition.

†Significant difference from treatment.

$\ddagger$ Significant difference from control. 

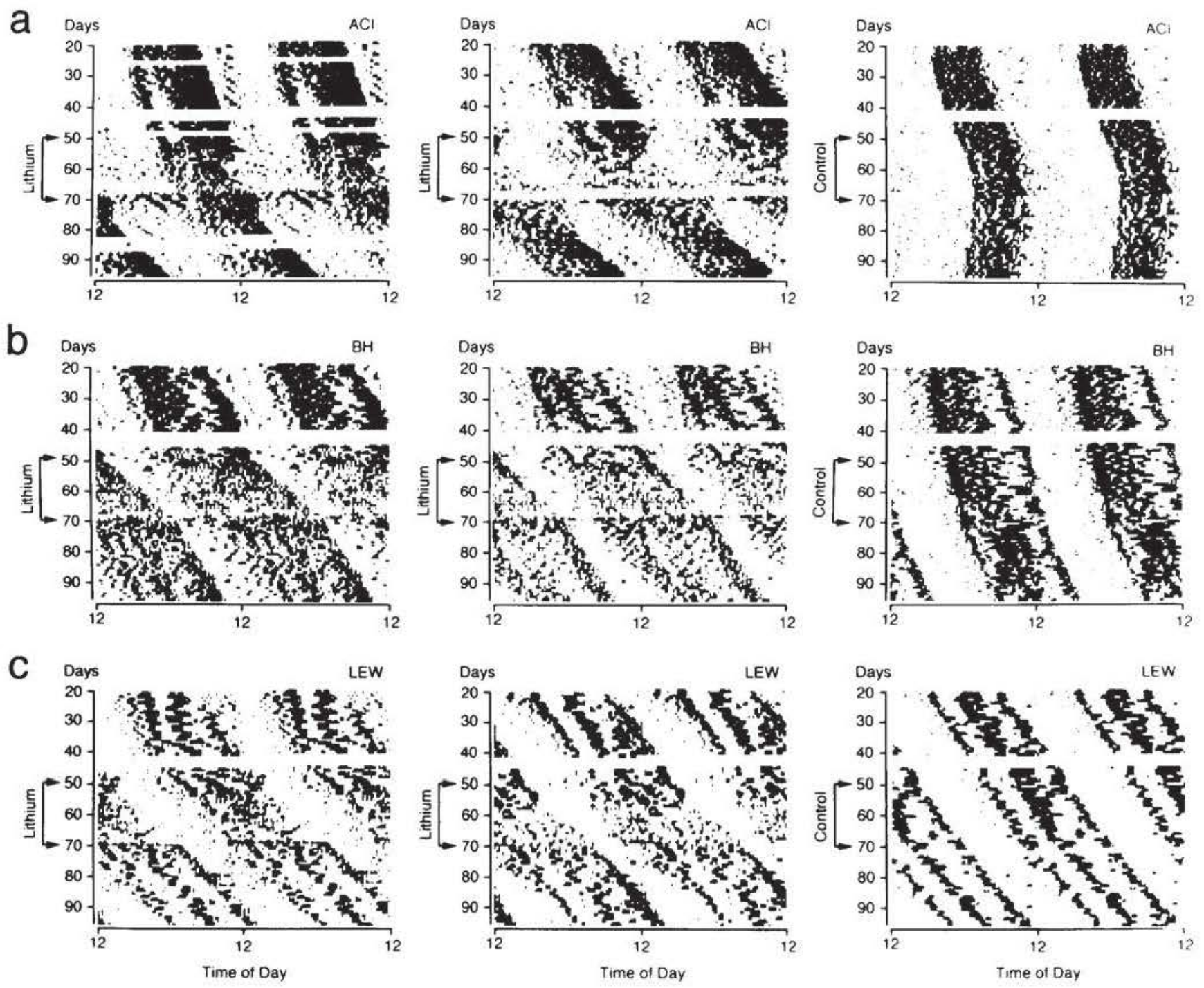

FIG. 1. Characteristic recordings of wheel-running activity from ACI (a), BH (b), and LEW rats (c). Numbers on the vertical axes denote days of experiment; numbers on the horizontal axes denote daytime hours. Activity records are plotted from the first day of constant darkness on (22nd day of experiment). They are shown as double plots to facilitate visualization of free-running rhythms. Each 48 -h period consists of 144 bins, where the height of each bin represents the number of impulses during a 20-min interval (20-200 impulses/bin). Following 28 days of baseline conditions, animals were fed either the standard diet (control) or a lithium diet containing $0.3 \% \mathrm{Li}_{2} \mathrm{CO}_{3}$ for 21 days.

After termination of lithium treatment, all animals showed a substantial increase in their wheel-running activity together with a loss of circadian organization lasting several days (most markedly seen in ACI and BH rats, Fig. 1a,b). However, when averaged over the last 3 weeks of withdrawal conditions, overall activity did not rise over treatment level and was significantly lower than during baseline (Table 3). Control animais also showed a small reduction in their overall activity, but this was not significant. During the last 20 days of the experiment, $\mathrm{BH}$ and LEW rats exhibited very distinct bouts of activity leading to a preponderance of ultradian frequencies in the power spectra (Fig. 2d,f).

Results for free-running period are summarized in Table 4. During lithium treatment, only $\mathrm{BH}$ rats showed a pronounced lengthening of their circadian period $(11 \mathrm{~min})$. In the two other strains, a lengthening of circadian period was detected only after lithium withdrawal. This effect was most pronounced in ACI animals (16.2 min), resulting in significant differences between experimental groups, $F(1,15)=7.27$, $p \leq 0.05$, and treatments, $F(2,14)=11.29, p \leq 0.01$, during withdrawal conditions. Correlation analysis revealed a small, but not significant correlation between total drug intake during the 21 days of lithium treatment and changes in period length. Because the experiment was terminated after 100 days, it is not known whether circadian periods would have returned to baseline values after a longer period of lithium withdrawal.

A correlational analysis (Table 5) comparing overall activity and circadian period during baseline, treatment, and withdrawal conditions, revealed a small negative correlation be- 
a
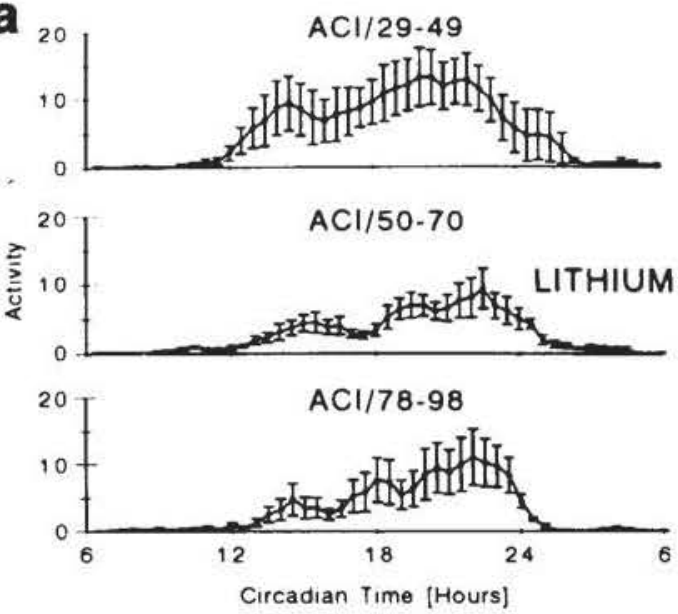

C
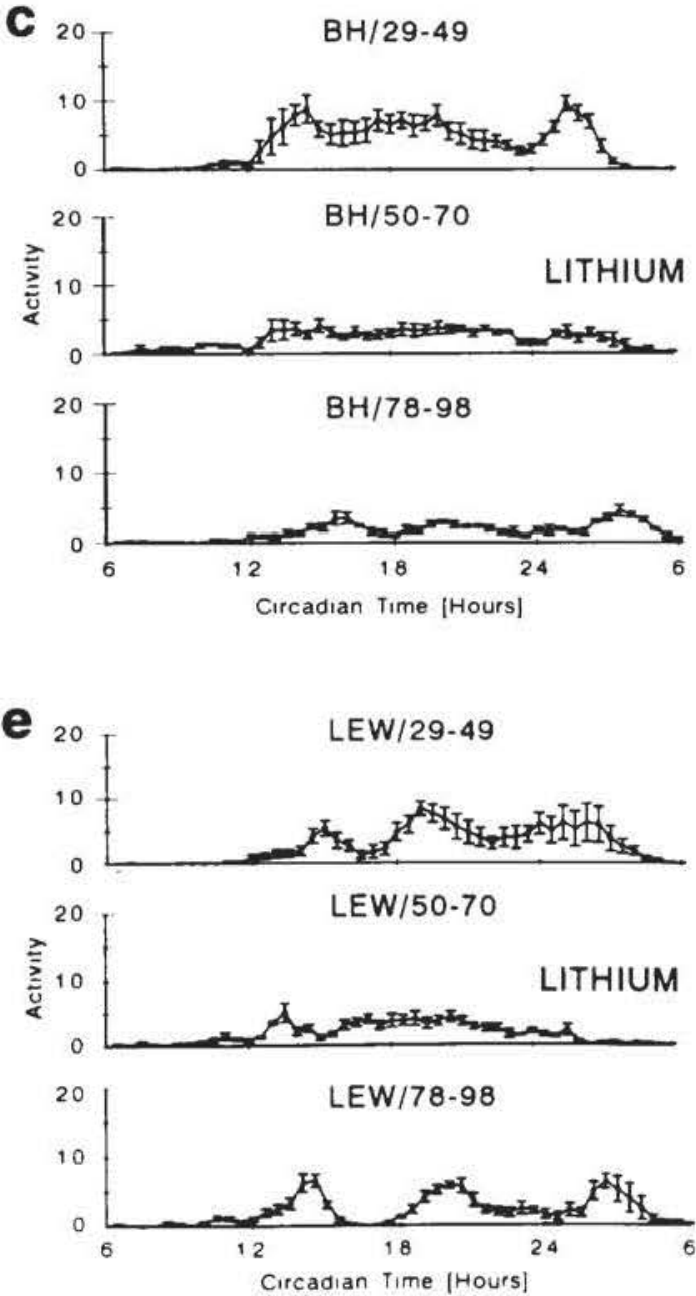
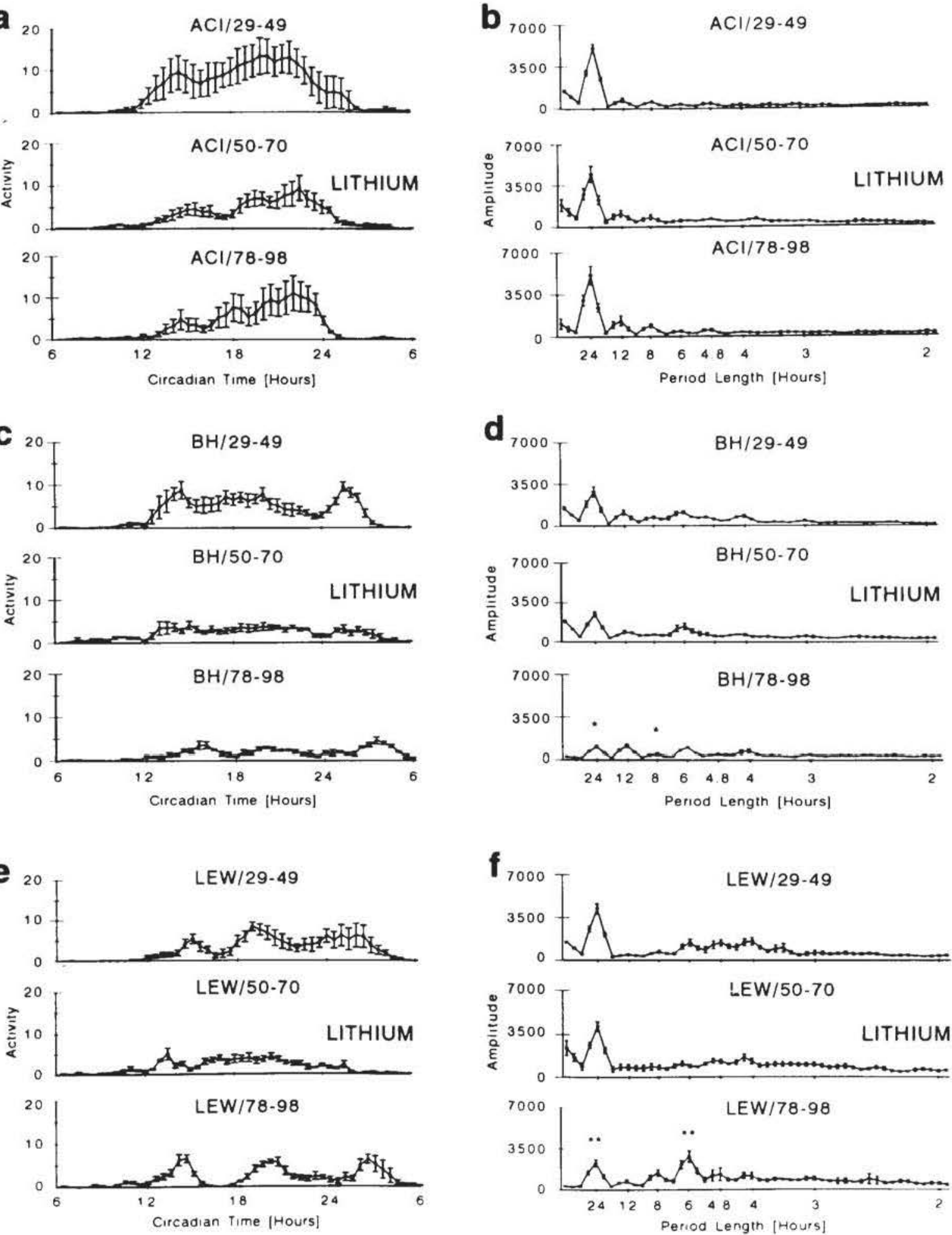

FIG. 2. Effects of lithium treatment. Left column: circadian waveform of wheel-running activity of $\mathrm{ACl}(\mathrm{a}, n=5)$, $\mathrm{BH}$ (c, $n=5$ ), and LEW (e, $n=6$ ) rats during baseline conditions (upper panel), lithium treatment (middle panel), and withdrawal (lower panel). First weeks of baseline and withdrawal conditions were omitted to avoid disturbance by transient effects. Thirtyminute mean values are plotted as a function of the free-running period with standard deviation between animals shown as vertical lines. Right column: average power spectra for strains ACI (b), BH (d), and LEW (f) calculated from spectral analyses of individual animals. The $95 \%$ confidence limits of spectral estimates are plotted as vertical lines. Asterisks mark estimates that are significantly different from corresponding values during baseline conditions $\left({ }^{*} p \leq 0.05 ;{ }^{* *} p \leq 0.01\right)$. Amplitudes of spectral estimates: $\mathrm{ACI}-24-\mathrm{h}_{\text {baseline }}=5029 \pm 254,24-\mathrm{h}_{\text {lithium }}=4477 \pm 692,24$ - $_{\text {withdrawal }}=5130 \pm 766 ; \mathrm{BH}-24-\mathrm{h}_{\text {baseline }}=2842 \pm$ $424,24-\mathrm{h}_{\text {lithium }}=2450 \pm 240,24-\mathrm{h}_{\text {withdrawal }}=1027 \pm 102 ; \mathrm{BH}-8-\mathrm{h}_{\text {baseline }}=706 \pm 108,8-\mathrm{h}_{\text {lithium }}=635 \pm 65,8$ - $\mathrm{h}_{\text {withdrawal }}=$ $443 \pm 80 ; \mathrm{LEW}-24-\mathrm{h}_{\text {baseline }}=4234 \pm 414,24-\mathrm{h}_{\text {lithium }}=4154 \pm 368,24-\mathrm{h}_{\text {withdrawal }}=2284 \pm 292 ; \mathrm{LEW}-6$ - $_{\text {bascline }}=1435 \pm$ $283,6-\mathrm{h}_{\text {lithium }}=919 \pm 143,6-\mathrm{h}_{\text {withdrawal }}=2833 \pm 451$. 
TABLE 3

EFFECTS OF CHRONIC LITHIUM TREATMENT ON OVERALL ACTIVITY LEVELS (IMPULSES/DAY) IN ACI, BH, AND LEW RATS

\begin{tabular}{crr}
\hline Treated Animals & $\begin{array}{c}\text { Controls } \\
(n=5) \\
\text { Mean } \pm \text { SE }\end{array}$ & $\begin{array}{c}(n=2) \\
\text { Mean } \pm \text { SE }\end{array}$ \\
\hline ACI & & \\
B & $1847 \pm 579$ & $1470 \pm 282$ \\
T & $843 \pm 217$ & $934 \pm 373$ \\
W & $957 \pm 310$ & $761 \pm 152$ \\
BH & & \\
B & $1291 \pm 206$ & $1120 \pm 352$ \\
T & $604 \pm 75$ & $986 \pm 319$ \\
W & $482 \pm 33$ & $706 \pm 230$ \\
LEW & & \\
B & $940 \pm 200$ & $884 \pm 446$ \\
T & $522 \pm 56$ & $628 \pm 335$ \\
W & $607 \pm 87$ & $443 \pm 250$ \\
E & $1360 \pm 236 \dagger$ & $1158 \pm 233$ \\
B & $657 \pm 86^{*}$ & $849 \pm 208$ \\
T & $682 \pm 120^{*}$ & $637 \pm 137$ \\
W & &
\end{tabular}

$\mathrm{F}_{\text {Strains }}(2,15)=1.02 \mathrm{NS}$.

$F_{\text {Groups }}(1,15)=0.00$ NS.

$\mathrm{F}_{\text {Strains, Groups }}(2,15)=0.11 \mathrm{NS}$.

Wilks' Lambda $\mathrm{F}_{\text {Treatments }}(2,14)=9.22 p \leq 0.01$.

Wilks' Lambda $\mathrm{F}_{\text {Strains,Treatments }}(4,28)=0.54$ NS.

Wilks' Lambda $\mathrm{F}_{\text {Groups, Treatments }}(2,14)=1.13 \mathrm{NS}$.

Wilks' Lambda $F_{\text {Strains, Treatments,Groups }}(4,28)=0.15$ NS.

For methods and notations, see Table 2.

tween activity and period for control animals $(r=-0.31$, NS). In the lithium-treated animals, a significant correlation between activity and period was found only for BH rats $(r=$ $-0.51, p \leq 0.05$ ). An additional covariance analysis of $\tau$, including activity as a covariate, revealed that $F$-values actually became smaller, indicating that activity was not only correlated with period, but also with the between group factors, i.e., experimental groups and treatment conditions. However, the effect of the covariate was rather small, indicating that the period lengthening effect of lithium cannot be explained simply by a decrease in overall activity.

\section{DISCUSSION}

This study investigated the effect of chronic lithium treatment on circadian activity rhythms in specific inbred strains of rats. The objective was to explore the possible interaction between pharmacological effects of lithium and feedback effects of activity on the circadian system.

The results of this study were generally consistent with previous studies demonstrating a period-lengthening effect of chronic lithium administration. However, the results also showed that the effects of lithium treatment on circadian activity rhythm are manifold and diverse. First, the present study demonstrated strain differences in the amount of lithium-induced period changes, i.e., LEW rats failed to show significant changes in period length, as well as in the timing of lithium-induced changes, i.e., during treatment (BH rats) or after withdrawal (ACI rats). Because we did not measure se- rum lithium levels during or at the end of the experiment, we do not know what levels of lithium were present during the withdrawal period. It may well be that lithium clearance was especially low in the ACI strain resulting in a prolonged elevation of lithium. This point needs further evaluation.

Previous studies demonstrating period changes either during (24) or after lithium treatment (41) may also reflect genetic differences, because different outbred strains of laboratory rats were used. A direct comparison, however, is impossible, because Stewart et al. (41) did not measure period length during treatment, and Kripke and Wyborney (24) provided no data before or after lithium application. So far, true strain-dependent ef fects of lithium on circadian periods have been described only in mice (33). Although these strain difference may be due to a number of physiological mechanisms ranging from differences in absorption of lithium through the intestinal tracts to differences in the sensitivity of the circadian system itself, they, nevertheless, indicate that individual differences in response to lithium $(4,15,16,25)$ may be caused by differences in the genetic background of the animals investigated.

Second, lithium treatment causes rather strong side effects, which complicate interpretation of its chronopharmacological and behavioral effects. It is now well documented that chronic lithium produces nephrogenic diabetes insipidus in animals as well as in humans $(10,11)$, resulting in an inability to concentrate urine, increased urine flow, and sodium loss. Furthermore, lithium increases thirst and water intake can rise as much as sixfold in rats (19). A common sign of lithium treat-

TABLE 4

EFFECTS OF CHRONIC LITHIUM TREATMENT ON THE FREE-RUNNING PERIOD $\tau$ (HOURS) OF CIRCADIAN WHEEL-RUNNING ACTIVITY RHYTHMS IN $\mathrm{ACI}, \mathrm{BH}, \mathrm{AND}$ LEW RATS

\begin{tabular}{|c|c|c|}
\hline Strains & $\begin{array}{l}\text { Treated Animals } \\
\qquad(n=5) \\
\text { Mean } \pm \text { SE }\end{array}$ & $\begin{array}{c}\text { Controls } \\
(n=2) \\
\text { Mean } \pm \text { SE }\end{array}$ \\
\hline \multicolumn{3}{|l|}{$\mathrm{ACl}$} \\
\hline B & $24.23 \pm 0.03$ & $24.17 \pm 0.00$ \\
\hline $\mathrm{T}$ & $24.18 \pm 0.07$ & $24.17 \pm 0.00$ \\
\hline w & $24.50 \pm 0.03$ & $24.21 \pm 0.15$ \\
\hline \multicolumn{3}{|l|}{$\mathrm{BH}$} \\
\hline B & $24.23 \pm 0.01$ & $24.21 \pm 0.03$ \\
\hline $\mathrm{T}$ & $24.42 \pm 0.02$ & $24.21 \pm 0.09$ \\
\hline W & $24.31 \pm 0.01$ & $24.25 \pm 0.06$ \\
\hline \multicolumn{3}{|l|}{ LEW } \\
\hline B & $24.25 \pm 0.03$ & $24.25 \pm 0.06$ \\
\hline $\mathrm{T}$ & $24.36 \pm 0.10$ & $24.29 \pm 0.03$ \\
\hline w & $24.42 \pm 0.00$ & $24.42 \pm 0.00$ \\
\hline \multicolumn{3}{|l|}{$\Sigma$} \\
\hline B & $24.24 \pm 0.02 \dagger$ & $24.21 \pm 0.03$ \\
\hline $\mathrm{T}$ & $24.32 \pm 0.05^{*}$ & $24.22 \pm 0.04$ \\
\hline W & $24.41 \pm 0.02 * \ddagger$ & $24.29 \pm 0.06$ \\
\hline \multicolumn{3}{|c|}{$\begin{array}{l}\mathrm{F}_{\text {Strains }}(2,15)=2.87 \mathrm{NS} . \\
\mathrm{F}_{\text {Groups }}(1,15)=7.27 p \leq 0.05 \\
\mathrm{~F}_{\text {Strains, Groups }}(2,15)=0.92 \mathrm{NS} \text {. } \\
\text { Wilks' Lambda } \mathrm{F}_{\text {Treatments }}(2,14)=11.29 p \leq 0.01 \\
\text { Wilks' Lambda } \mathrm{F}_{\text {Strains, Treatments }}(4,28)=1.19 \mathrm{NS} \text {. } \\
\text { Wilks' Lambda } \mathrm{F}_{\text {Groups, Treatments }}(2,14)=1.45 \mathrm{NS} \text {. } \\
\text { Wilks' Lambda } \mathrm{F}_{\text {Strains, Treatments, Groups }}(4,28)=1.22 \mathrm{NS} \text {. }\end{array}$} \\
\hline
\end{tabular}

For methods and notations, see Table 2. 
TABLE 5

CORRELATION COEFFICIENTS (PEARSON'S $r$ ) BETWEEN OVERALL LEVEL OF ACTIVITY (IMP. /DAY) AND CIRCADIAN PERIODS $\tau$ (HOURS) IN THE THREE INBRED STRAINS $\mathrm{ACl}, \mathrm{BH}, \mathrm{AND}$ LEW

\begin{tabular}{lcc}
\hline Strains & Treated Animals & Controls \\
\hline$\Sigma$ & -0.18 & -0.31 \\
ACI & -0.09 & $-0.51^{*}$ \\
BH & $-0.51^{*}$ & 0 \\
LEW & -0.11 & -0.23 \\
\hline
\end{tabular}

${ }^{*} p=\leq 0.05$.

ment in rodents is a dramatic weight loss, which can result in the death of single animals $(4,35)$. In the present study, two rats died during the experiment. Although recent studies showed that lithium toxicity can be reduced by dietary potassium $(19,20)$ or calcium supplementation $(18)$, some adverse side effects seem to be unavoidable. Therefore, one cannot completely rule out that the observed effects of lithium treatment are - at least partly - due to the side effects of lithium on food intake, body weight, and other physiological functions.

Finally, it has been suggested that the route and timing of lithium treatment may be important for its action on circadian rhythms (23). When lithium is administered in the food or drinking water, it is mostly digested during the active phase of the animal, i.e., at night. Administration via osmotic pumps, on the other hand, results in continuous deliverance of lithium. Several studies $(13,24,33)$ using oral lithium administration found a lengthening of circadian period during lithium treatment that is comparable to the period changes observed in the present study. On the other hand, contradictory results were obtained when lithium was applicated subcutaneously by osmotic pumps: Kripke et al. (23) found no effect of lithium on circadian period, whereas Klemfuss and Kripke (19) saw a phase delay in entrained rhythm indicating an increase of internal period. As both oral and SC application lead to rather stabile serum lithium levels (28), fluctuations in drug dose induced by rhythmic feeding cannot explain these contradictions.

Apart from changes of period, the present study showed a marked decline of activity and a weakening of the circadian pattern during lithium treatment. This is more in accordance with clinical observations (37) than with other chronobiological experiments that failed to demonstrate a significant effect of lithium on the level or distribution of activity in rats (24), Syrian hamsters (4), or squirrel monkeys (46). A lithiuminduced decline of circadian amplitude, however, was reported for rhythms of body temperature (28) and retinal disc shedding (36). It remains unclear if the side effects observed in our study contributed to the reduction of activity. As a similar loss of body weight (46) and other side effects (4) did not induce changes in activity level, the influence of side effects seems to be minor.

Recent observations $(7,52,54)$ demonstrating that changes in the free-running period may also be induced by alterations of the activity level raised the question whether lithium may affect the circadian pacemaker indirectly through activity feedback. Unfortunately, only few investigations of lithium effects on circadian rhythms have quantified changes in overall activity $(4,46)$. The only study correlating changes in activity level and circadian period before and during lithium treatment found little evidence for a causal relation between activity level and period length (38). This finding is supported by the present study in which correlational and covariance analysis revealed a negative correlation between activity level and circadian period only in $\mathrm{BH}$ rats, but not as a general effect. Thus, there is some evidence that lithium may affect the circadian pacemaker indirectly through activity feedback in this particular strain. However, even in this strain the effect was rather small and did not account for the total amount of the observed period change. As lithium sensitive secondmessenger systems in the SCN are known $(27,30)$, direct and indirect effects may play synergetically together.

After lithium treatment was terminated, a short-time increase in activity was observed accompanied by a nearly complete loss of the circadian activity pattern. Both the activity decrease during treatment and the transient activity increase after withdrawal parallel changes in central nervous catecholamine-metabolism (1). As catecholamines are known to increase activity (3), changes in catecholamine level may at least partly be responsible for the observed changes of activity. Furthermore, Lemmer et al. (26) found differences in the catecholamine-metabolism of the same inbred strains as the ones used in this study, providing a possible explanation for the strain dependent reactions.

The question arises why ANOVA failed to verify the small but rather obvious differences in period and in overall activity within strains. Two explanations are possible: first, individual values of animals belonging to the same strain or group could have been very diverse. However, Fig. 2 and Tables 3 and 4 show that this was not the case. A second explanation may be a general tendency to lower activity levels and longer periods with increasing age and body weight (32). The parallel changes in treated and untreated animals could have prevented ANOVA from rejecting zero-hypothesis of repeated measurements (all changes are the same), thus obscuring interactions between strains and experimental groups, which were clearly detected by separate analyses of treated animals or singletreatment conditions.

During withdrawal, $\mathrm{BH}$ and LEW rats showed very distinct activity bouts, although overall activity was rather low. This suggests that the multimodal activity patterns of these strains are caused by multiple oscillatory units, whose coupling may be weakened by a low activity level (49). Lithium seems to facilitate desynchronization of circadian oscillators. For example, lithium treatment resulted in an increased splitting of activity rhythms in rats (24) or the incidence of colliding of activity onset and of fset in hamsters (29), suggesting that lithium may weaken the mutual interaction between coupled oscillators, which could also account for its period lengthening effect.

In conclusion, the present study confirmed previous findings on the lithium-induced lengthening of circadian period. Furthermore, our data support the traditional interpretation that lithium lengthens circadian period by a direct pharmacological effect on the circadian pacemaker rather than through indirect effects of activity feedback. Nevertheless, the effects of lithium on circadian rhythms are far from being well understood or even documented adequately despite its long-time use in chronobiology. Strain-dependent differences in brain metabolism may provide a powerful tool for further studies and lead one step closer to an understanding of lithium effects on chronobiological and clinical grounds.

\section{ACKNOWLEDGEMENTS}

This research was supported by a grant from the Deutsche Forschungsgemeinschaft (Wo 354/3-2). The authors wish to thank Rita Hellmann for technical assistance and Ulla Siebert for mental support. 


\section{REFERENCES}

1. Ahluwalia, P.; Singhal, R. L. Comparison of the changes in central catecholamine systems following short- and long-term lithium treatment and the consequences of lithium withdrawal. Neuropsychobiology 12:217-223; 1984

2. Aschoff, J.; Figala, J.; Pöppel, E. Circadian rhythms of locomotor activity in the golden hamster (Mesocricetus auratus) measured with two different techniques. J. Comp. Physiol. Psychol. $85: 20-28 ; 1973$.

3. Beninger, R. J. The role of dopamine in locomotor activitiy and learning. Brain Res. Rev. 6:173-196; 1983.

4. Delius, K.; Günderoth-Palmowski, I.; Krause, I.; Engelmann, W. Effects of lithium salts on the behaviour and the circadian system of Mesocricetus auratus. J. Interdiscipl. Cycle Res. 15(4):289299; 1984.

5. Duncan, W. C.; Tamarkin, L.; Sokolove, P. G.; Wehr, T. A. Chronic clorgyline treatment of Syrian hamsters: An analysis of effects on the circadian pacemaker. J. Biol. Rhythms 3(4):305$322 ; 1988$.

6. Edgar, D. M.; Kilduff, T. S.; Martin, C. E.; Dement, W. C. Influence of running wheel activity on free-running sleep wake and drinking circadian-rhythms in mice. Physiol. Behav. 50:373378; 1991.

7. Edgar, D. M.; Martin, C. E.; Dement, W. C. Activity feedback to the mammalian circadian pacemaker: Influence on observed measures of rhythm period length. J. Biol. Rhythms 6:185-199; 1991.

8. Engelmann, W. A slowing down of circadian rhythms by lithium ions. Z. Naturforsch. 28c:733-736; 1973.

9. Enright, J. T. The search for rhythmicity in biological time-series. J. Theor. Biol. 8:426-468; 1965.

10. Forrest, J. N.; Cohen, A. D.; Torretti, J.; Himmelhoch, J. M.; Epstein, F. H. On the mechanism of lithium-induced diabetes insipidus in man and the rat. J. Clin. Invest. 53:1115-1123; 1974.

11. Glen, I. Practical aspects of long-term treatment with lithium. J. Psychopharmacol. Suppl. 6(2):330-333; 1992.

12. Goodwin, F. K.; Wirz-Justice, A.; Wehr, T. A. Evidence that the pathophysiology of depression and the mechanism of action of antidepressant drugs both involve alterations in circadian rhythms. In: Costa, E.; Racagni, G., eds. Typical and atypical antidepressants: Clinical practice. New York: Raven Press; 1982:1-11.

13. Groos, G. A.; Mason, R. An electrophysiological study of the rat's suprachiasmatic nucleus: $A$ locus for the action of antidepressants, J. Physiol. (Lond.) 330:40P; 1982.

14. Halberg, F.; Panofsky, H. I. Thermo variance spectra; Methods and clinical illustrations. Exp. Med. Surg. 19:285-321; 1961.

15. Hofmann, K.; Günderoth-Palmowski, M.; Wiedenmann, G.; Engelmann, W. Further evidence for period lengthening effects of $\mathrm{Li}^{+}$on circadian rhythms. Z. Naturforsch. 33c:231-234; 1978.

16. Johnsson, A.; Engelmann, W.; Pflug, B.; Klemke, W. Influence of lithium ions on human circadian rhythms. Z. Naturforsch. $35 \mathrm{c}: 503-507 ; 1980$.

17. Klemfuss, H. Rhythms and the pharmacology of lithium. Pharmacol. Ther. 56:53-78; 1992.

18. Klemfuss, H.; Bauer, T. T.; Greene, K. E.; Kripke, D. F. Dietary calcium blocks lithium toxicity in hamsters without affecting circadian rhythms. Biol. Psychiatry 31:315-321; 1992.

19. Klemfuss, H.; Kripke, D. F. Potassium reduces lithium toxicity: Circadian rhythm actions are maintained. Life Sci. 40:2531-2538; 1987.

20. Klemfuss, H.; Kripke, D. F. Potassium advances circadian activity rhythms: Interactions with lithium. Brain Res. 492:300-304; 1989.

21. Klemfuss, H.; Kripke, D. F. Effects of lithium on circadian rhythms. In: Lemmer, B., ed. Chronopharmacology. Cellular and biochemical interactions. New York: Marcel Dekker; 1989: 281-298.

22. Kripke, D. F.; Drennan, M. D.; Elliott, J. A. The complex circadian pacemaker in affective disorders. In: Touitou, Y.; Haus, E., eds. Biologic rhythms in clinical and laboratory medicine. Berlin: Springer Verlag; 1992:265-276.

23. Kripke, D. F.; Mullaney, D. J.; Gabriel, S. The chronopharmacology of antidepressant drugs. In: Reinberg, A.; Smolensky, M.; La Breque, G., eds. Annual review of chronopharmacology, vol. 2. Oxford: Pergamon Press; 1985:275-289.

24. Kripke, D. F.; Wyborney, V. G. Lithium slows rat circadian activity rhythm. Life Sci. 26:1319-1321; 1980.

25. Kripke, D. F.; Mullaney, D.J.; Atkinson, M.; Wolf, S. Circadian rhythm disorders in manic-depressives. Biol. Psychiatry 13:335$351 ; 1978$.

26. Lemmer, B.; Caspari-Irving, G.; Weimer, R. Strain-dependency in motor activity and in concentration and turnover of catecholamines in synchronized rats. Pharmacol. Biochem. Behav. 15:173178; 1981.

27. Mason, R.; Biello, S. M. A neurophysiological study of a lithiumsensitive phosphoinositide system in the hamster suprachiasmatic (SCN) biological clock in vitro. Neurosci. Lett. 144:135-138; 1992.

28. McEachron, D. L.; Kripke, D. F.; Sharp, F. R.; Lewy, A. J.; McClellan, D. E. Lithium effects of selected circadian rhythms in rats. Brain. Res. Bull. 15:347-350; 1985.

29. Mrosovsky, N.; Hallonquist, J. D. Colliding of activity onset and offset: Evidence for multiple circadian oscillators. J. Comp. Physiol. 159:187-190; 1986.

30. Nadakavukaren, J. J.; Welsh, D. K.; Reppert, S. M. Aluminum fluoride reveals a phosphoinositide system within the suprachiasmatic region of rat hypothalamus. Brain Res. 507:181-188; 1990.

31. Panofsky, H.; Halberg, F., II. Thermo variance spectra; Simplified computational example and other methodology. Exp. Med. Surg, 19:323-338; 1961.

32. Peng, M.-T.; Jiang, M.-J.; Hsü, H.-K. Changes in running-wheel activity eating and drinking and their day/night distributions throughout the life span of the rat. J. Gerontol. 3:339-347; 1980.

33. Possidente, B.; Exner, R. Gene-dependent effect of lithium on circadian rhythms in mice. Chronobiol. Int. 3(1):17-21; 1986.

34. Pratt, B. L.; Goldman, B. D. Environmental influences upon circadian periodicity of Syrian hamsters. Physiol. Behav. 36(1): 91-95; 1986.

35. Reinhard, P. Die Wirkung von Lithium auf das circadiane Verhalten von Schaben und Hamstern in Lichtprogrammen verschiedener Periodenlänge. Tübingen: Dissertation; 1983.

36. Reme, C. E.; Braschler, U.; Wirz-Justice, A.; Munz, K. Diskshedding in the rat retina: Lithium dampens the circadian rhythm but potentiates the light response. Brain Res. 523:167-170; 1990.

37. Schou, M. Clinical aspects of lithium in psychiatry. In: Birch, N J., ed. Lithium and the cell. London: Academic Press; 1991:1-6.

38. Schull, J.; McEachron, D. L.; Adler, N. T.; Fiedler, L.; Horvitz, J.; Noyes, A.; Olson, M.; Shack, J. Effects of thyroidectomy, parathyroidectomy and lithium on circadian wheelrunning in rats. Physiol. Behav. 42:33-39; 1986.

39. Shioiri, T.; Takahashi, K.; Yamada, N.; Takahashi, S. Motor activity correlates negatively with free-running period, while positively with serotonin contents in $\mathrm{SCN}$ in free-running rats. Physiol. Behav. 49:779-786; 1991.

40. Sokolove, P. G.; Bushell, W. N. The chi square periodogram: its utility for analysis of circadian rhythms. J. Theor. Biol. 72:131$160 ; 1978$.

41. Stewart, K. T.; McEachron, D. L.; Rosenwasser, A. M.; Adler, N. T. Lithium lengthens circadian period but fails to counteract behavioral helplessness in rats. Biol. Psychiatry 30:515-518; 1991.

42. Strumwasser, F.; Viele, D. P. Lithium increases the period of a neuronal circadian oscillator. Soc. Neurosci. Abstr. 241.5; 1980.

43. Van Reeth, O.; Turek, F. W. Stimulated activity mediates phase shifts in the hamster circadian clock induced by dark pulses or benzodiazepines. Nature 339:49-51; 1989.

44. Wehr, T. A.; Lewy, A. J.; Wirz-Justice, A.; Craig, C.; Tamarkin, L. Antidepressants and a circadian phase-advance hypothesis 
of depression. In: Collu, R.; Ducharme, J. R.; Barbeau, A.; Tolis, G., eds. Brain peptides and hormones. New York: Raven Press; 1982:263-276.

45. Wehr, T. A.; Wirz-Justice, A. Circadian rhythm mechanisms in affective illness and in antidepressant drug action. Pharmacopsychiatry $15: 31-39 ; 1982$.

46. Welsh, D. K.; Moore-Ede, M. C. Lithium lengthens circadian period in a diurnal primate, Saimiri sciureus. Biol. Psychiatry 28: $117-126 ; 1990$.

47. Wirz-Justice, A.; Campbell, I. C. Antidepressant drugs can slow or dissociate circadian rhythms. Experientia 38:1301-1309; 1982.

48. Wirz-Justice, A.; Wehr, T. A. Neuropsychopharmacology and biological rhythms. Adv, biol. Psychiatry 11:20-34; 1983.

49. Wollnik, F. Strain differences in the pattern and intensity of wheel running activity in laboratory rats. Experientia 47:593-598; 1991.

50. Wollnik, F. Effects of chronic administration and withdrawal of antidepressant agents on circadian activity rhythms in rats. Pharmacol. Biochem. Behav. 43:549-561; 1992.

51. Wollnik, F.; Döhler, K. D. Effects of adult or perinatal hormonal environment on ultradian rhythms in the locomotor activity of laboratory LEW/Ztm rats. Physiol. Behav. 38:229-240; 1986.

52. Yamada, N.; Shimoda, K.; Ohi, K.; Takahashi, S.; Takahashi, $\mathrm{K}$. Free-access to a running wheel shortens the period of freerunning rhythm in blinded rats. Physiol Behav. 42:87-91; 1988.

53. Yamada, N.; Shimoda, K.; Takahashi, K.; Takahashi, S. Change in period of free-running rhythms determined by two different tools in blinded rats. Physiol. Behav. 36(2):357-362; 1986.

54. Yamada, N.; Shimoda, K.; Takahashi, K.; Takahashi, S. Relationship between free-running period and motor activity in blinded rats. Brain. Res. Bull. 25:115-119; 1990.

55. Yamada, S. Changes in dopaminergic and dopaminoceptive functions of the rat brain after repeated administration of methamphetamine. Taniguchi Symp. Brain Sci. 14:203-213; 1991. 